\title{
A New Method of Futures Hedging Used in The Electricity Market
}

\author{
Jin Fei, Xing Chao \\ State Grid Hebei Electric Power Research Institute, Shijiazhuang 050021, China
}

15028125563@163.com

Keyword: risk hedging, chaos theory, electricity marke.

\begin{abstract}
With the reforming in the power system, the electricity market is gradually opening up and all kinds of guiding policy come on intensively, the operating environment of thermal power enterprises will gradually change. The change will lead to more intense competition between the power generation industry and further liberalization of the electricity market.This article describes a new method of risk hedging in the electricity market system under the future system. Using the changes in the fair value of the hedging instruments to hedge the fair value of the hedging project, and to prevent and transfer the risk.
\end{abstract}

\section{Introduction}

The price of steam coal is an important basis for the operating and making policy of power enterprises.The electricity price is relatively stable and unchanging, while the price of steam coal in the spot market is fragmented, short-lived. This situation is not conducive for the enterprises to make correct decision.

The new method of coal-electricity price linkage which uses the changing of $5 \%$ of the coal electricity price as the trigger condition for price adjustment is carried out from the early 2013's.Coal price had fallen from its peak from the end of 2011. The price of latest issue of the Bohai Rim coal is below 500 yuan / ton.The fluctuation range of electricity price has far exceeded the trigger condition.

Tariff reduction policy that makes the price drop 0.01 yuan/kWh has been finalized on August 6 , 2015.Every region drops somewhat different.The price of coal adjusts to 20-25 yuan/ton relatively. It is a big negative for the coal market. After the early coal price dropping, the implementation of limited production price and import restrictions will further support the price of coal.

Therefore, the power companies can use risk aversion such as hedging to enable the power industry stable, to effectively alleviate the "coal-electricity price linkage" pressure, to increase the speaking right for the power companies, to achieve two methods to avoid the risk of coal price fluctuations.

\section{Analysis of traditional hedging method}

The situation is that electricity sales price is fixed but coal price changes with the market.In order to avoid the risk of coal price rising, we can purchase electricity futures in the futures market. After that, companies can do some adjustment according to market conditions.At last, buying the corresponding value of coal and building a futures contract to avoid risk.

\subsection{Beginning of the strategy}

In the early futures hedging strategy, the most important thing is to choose time and amount of hedging.The time concludes two sides: enter point and delivery point.For the thermal power enterprises, when you predict that coal price will rise according to market information, you can purchase hedging timely.

\subsection{Medium-term of the strategy}

Once we determin the time and amount of the hedging, we can adjust the policy flexibly according to the market situation.We must control the group difference(the difference between commodity spot price and futures price at the same time) to ensure hedging results. 


\subsection{Later stage of the strategy}

If the liquidation before the expiration of futures contracts,it is time to seng out the contracts; If the futures contract expires until maturity,it is time to send the coal.

Traditional futures hedging method is easy to understand and convenient to use.It only demands historical price information.Only considering risk regardless of income is its disadvantage.

\section{Analysis of new futures method}

\subsection{Analysis of demand by Season}

Overall, along with the increase of domestic steam coal production in recent years,the entire industry falls into a pattern of excess supply,but the supply still exhibits regular seasonal characteristics:

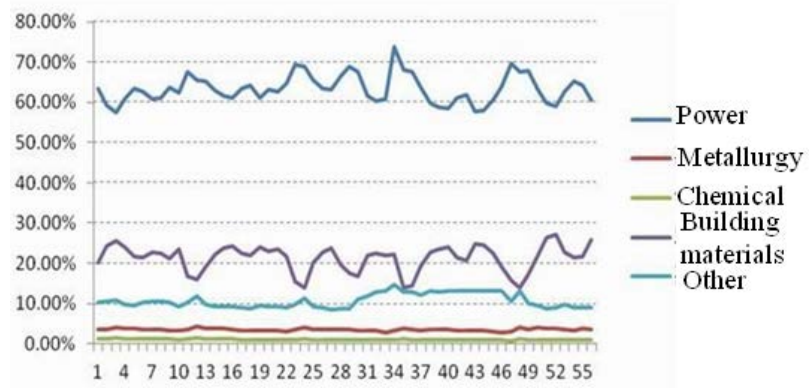

Fig1.Steam Coal demand by profession

Coal demand is weak due to the seasonal impact every month in the first half year except March.The reason why coal demand rebounded is that industrial demand for electricity after the Spring Festival holiday rised.Domestic thermal power accounts for about $80 \%$, the hydroelectric power accounts for $15 \%$.

Domestic hydropower capacity often shows an increasing trend from February to July,and starts to decrease from August to next February.Demand for electricity increases as temperature rises in July and August,so thermal power will significantly increase,the demand for coal also shows an increasing trend as well.Coal is purchased for the winter storage from the beginning of October,accordingly purchasing demand for thermal coal rises again until the end of the year.

\subsection{Analysis of hedging trend based on Chaos Theory}

According to the law of the seasonal cycle of steam coal, steam coal demand may rebound after the Spring Festival holiday in February in the first half of the year, in the rest the demand are in a weak period. Thermal power increases from August in summer, thermal coal futures prices also rises up from October to next January.

In the situation of clear trend, appropriate technical assistance judgment system can ensure coal futures spread risk and can be the key of return guarantees.Technical System is based on Chaos Theory, the core idea is divided into two parts:

1) mathematical statistics model of coal futures

RSV assignment :( closing price -the lowest value of the lowest price in 19 days) / (the highest value of the highest price in 19 days-the lowest value of the lowest price in 19 days) * 100

$\mathrm{K}$ assignment: the moving average in 9 days[the 1st weights] of RSV

$\mathrm{D}$ assignment: the moving average in 9 days[the 1st weights] of $\mathrm{K}$

J assignment: $3 * \mathrm{~K}-2 * \mathrm{D}$

Output MA3: the simple moving average in 38 days of closing price

Output MA4: the simple moving average in 60 days of closing price

2) Trend Judgment Rule based on Chaos

First determine all coal futures peak price HHV within a certain time period, and connect them into a line; Determine all coal futures valley price LLV , and connect them into a line.After that,we can get chaotic interval composed of two rolling lines.Steam coal futures price will scroll in this interval before clear trend forms.

Then, use two moving averages on behalf of volatility trend of steam coal price, one for fast line, 
the other for the slow line.The two lines represent the volatility of coal price in short-term and long-term separately.

When the two moving averages fluctuate between HHV and LLV, it is can be considered that the price is in the chaotic interval at this time, we should wait ;

When two moving averages clearly break of HHV or LLV and maintain a direction of motion, it is indicated that the trend has generated. We should refer to the seasonal fundamentals mentioned above to take proper technical operations.

The rolling cycle selection of HHV and LLV is critical in the chaotic process. If the selection period is short, it cannot reflect the trend , if the selection period is too long, the reaction will be too slow.After making optimization and improvement to the above algorithm,the criteria as:

Take the medium price of steam coal futures in the same day

TAX:=(the highest price of steam coal in the same day+the lowest price of steam coal in the same day)/2;

Take the weighted moving average price of TAX in the day before

MX:=REF(SMA(TAX,18,1),1);

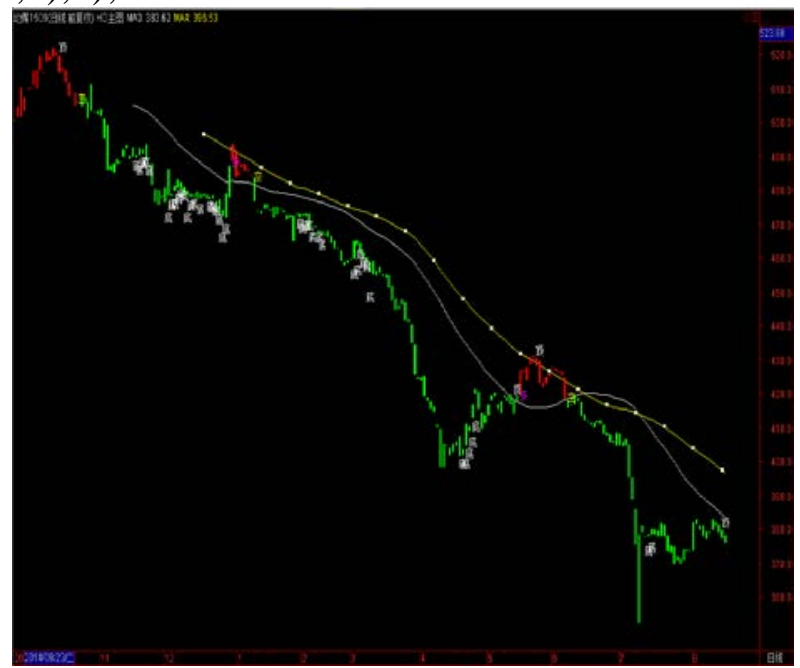

Fig2.Trend of steam coal futures

The results indicate that chaos system can guide the power company to find the trend of steam coal price in steam coal futures in TC 1509 contract.So futures trading can be carried out to hedge market risk when normal production is in progress.

\section{Specific methods of steam coal futures hedging usd by power companies}

First, it shoule be clear that power companies are processors in steam coal circulation. The procurement price of steam coal and product sale price are not time-synchronized so there is a certain cost risk of production and operation for power companies.

A power plant is expected to purchase 20,000 tons of steam coal in December.Since the electricity price is determined basically, profit targets can be achieved by simply locking procurement cost.Assume profit targets can be achieved when coal price is less than 550 yuan/ton, hedging is bought on August 20th. 


\begin{tabular}{|c|c|c|}
\hline \multirow{2}{*}{ August 20th } & $\begin{array}{c}\text { spot market } \\
\text { Planning to buy 20 } \\
\text { thousand tons of power } \\
\text { coal on December 10th, } \\
\text { 510yuan/ton }\end{array}$ & $\begin{array}{c}\text { futures market } \\
\text { January contract 20 } \\
\text { thousand tons, } \\
580 \text { yuan / ton }\end{array}$ \\
\hline December 10th & $\begin{array}{c}\text { As the price increases, The } \\
\text { final purchase price of 650 } \\
\text { yuan / ton }\end{array}$ & $\begin{array}{c}\text { Futures prices also } \\
\text { rose 140 yuan / ton, } \\
\text { Sell futures to 720 } \\
\text { yuan / ton price }\end{array}$ \\
\hline Profit and loss & $\begin{array}{c}\text { Procurement costs } \\
\text { increased by 2 million 800 } \\
\text { thousand yuan }\end{array}$ & $\begin{array}{c}\text { Futures earnings 2 } \\
\text { million 800 thousand } \\
\text { yuan }\end{array}$ \\
\hline Hedging effect & $\begin{array}{c}\text { Futures earnings to make up for the increase in the } \\
\text { cost of spot and prevent the loss of cost fluctuations }\end{array}$ \\
\hline
\end{tabular}

\section{Conclusion}

The cost of electricity generation in business depends largely on the price of steam coal. Price of steam coal in spot market is dispersed, ephemeral, so it is not conducive for business to make proper decisions.The power companies can use risk aversion such as hedging to avoid the risk of coal price fluctuations.

The paper proposes a futures system based on chaos rule after analyzing the traditional futures hedging method.Combined with the fundamentals and technicals,it puts forward a mean that power enterprises can discover price,guide production,avoid risk by using financial market method.

Power companies can also take advantage of physical delivery mechanism of futures market to procure some coal.It is safe for the production and operation.

\section{Reference}

[1]. Kupiec P H,Techniques for Verifying the Accuracy of Risk Measurment Models,The Journal of Derivatives,1995,3(2):73-84.

[2]. Herbst A F,Convergence-Asjusted Composite Hedging,Journal of Fanancial Engineering, 1994,3(2):156-67 